\title{
Complementary and Alternative Medicine Use among Elderly Diabetic Patients attending Assiut University and Health Insurance Hospitals
}

\author{
Asmaa Massod Attia, Safaa Ahmed Kotb, Ekram Mohamed Abdel Khalek, \& Asmaa Kamal Hassan. \\ Nursing Specialist in Assiut Chest Hospital. \\ Community Health Nursing.Faculty of Nursing, Assiut University. \\ Public Health and Community Medicine Faculty of Medicine, Assiut University
}

\begin{abstract}
:
Background: Diabetes among elderly population is difficult because of complex co-morbid conditions and the generally lower functional status of elderly patients. In recent years, there is a rising concern that many patients use complementary and alternative medicine (CAM). Aim of the study: Determine the percentage of CAM use and its related factors in elderly diabetic patients attending diabetes clinics in Assiut city. Subjects and Methods: crosssectional study was done. The data for this study were collected with 400 elderly diabetic patients attending diabetes outpatient clinics of Assiut University and Health Insurance Hospitals. A semi-structured questionnaire was used for data collection from the first day of September 2013 to the first week of October 2013. Data was analyzed using SPSS version 16. Results: About one third (33.8\%) of the respondents used CAM in addition to conventional medicine. Most common type used was herbal medicine. The CAM use was more frequent among male patients, aged 65- $<70$ years, university educated and urban residents. Conclusion: About one third of the studied elderly diabetic patients used CAM and conventional medicine in managing their illness There is statistical significant difference between CAM use and sex and level of education of our respondents. Recommendations: Evidencebased CAM information should be provided to patients as part of diabetes routine management and counseling.
\end{abstract}

Keywords: CAM, use, elderly, diabetics.

\section{Introduction:}

Diabetes mellitus (DM) is a major public health problem, which can cause serious complications; it is amongst the fifths leading causes of death worldwide. This problem is particularly relevant to the elderly. Diabetes is a common problem in older adults, approximately $20 \%$ of individuals over 65 years of age have diabetes mellitus, and almost half of these individuals have not been diagnosed. However, there are widespread misconceptions about possible consequences of uncontrolled hyperglycemia, the rate at which diabetic complications develop and the role of multidisciplinary managements (Franklin et al., 2011).

Global estimates of the prevalence of diabetes for 2011 is around $6.4 \%$, affecting 285 million adults and will increase to $7.7 \%$ and 439 million adults by 2030 . In United States of America, DM is considered the seventh leading causes of death that affected $23.7 \%$ of population and will increase to $29.6 \%$ by year 2030. In age 65 years or older DM is estimated to affect 10.9 million of all people in this age group. In other hand, the prevalence of DM in Egypt is estimate $7.3 \%$ and it will be risen to $12.4 \%$ by year 2030 (CDC, 2011; WHO, 2011).

Anti diabetic drugs are medicines that help control blood sugar levels in people with diabetes mellitus, but most drugs for diabetes have a dangerous side effect. The first registered use of herbal extracts as anti-diabetic drugs was by Indians in the Amazon Basin for the treatment of Type 2 diabetes, and today promoted as vegetable insulin but not formally an insulin analog (Abd El- Maksoud et al., 2009).

Complementary and alternative medicine refers to a wide range of clinical therapies outside of conventional medicine. The term "complementary" refers to therapies that are used in conjunction with conventional medicine, whereas "alternative medicine" includes therapies that are used in place of conventional medicine. The term "integrative medicine" has been advocated by some CAM providers and researchers as representing a combination of conventional medicine, CAM, and evidence-based medicine. Because patients with diabetes often take multiple prescription medications, there exists the potential for herb-drug and herbdietary supplement interactions, leading to adverse events. At least $63 \%$ of the general populations do not disclose use of CAM therapies to their physicians (NCCAM, 2010).

Complementary and alternative medicine is also raising academic, industrial, and public interest as an option to be added to the constantly growing therapies for diabetes. The National Health and Nutrition Examination Survey found that $48 \%$ of

Vol , (2) No , (3) June 2014 
diabetics use CAM. Diabetics are 1.6 times more likely to use CAM than non-diabetics. However, only $33 \%$ of patients using natural supplements or vitamins inform their health care provider (McWhorter, 2009; Forouhar and Paul, 2012).

Complementary and alternative medicine is attracting more and more attention within the context of health care provision and health sector reform. Practicing CAM is not free of contradictory views and reactions ranging from enthusiasm to skepticism. Use of CAM remains widespread in developing countries and is increasing rapidly in developed countries. Cultural beliefs and practices often lead to self-care, home remedies or consultation with traditional healers, particularly in deprived areas away from high quality health care such as in rural communities (Saad et al., 2008).

Whilst there is little published literature that describes CAM use in Egypt. CAM use among the patients was found to be $41.7 \%$ (Khalil et al., 2013). Although elderly patients with Type (2) diabetes actually use CAM, the benefits in the management of diabetes and the patterns of use are unknown. There is no relevant study has been conducted among elderly patients with Type (2) diabetes in Assiut Governorate.

Nurses, as health care providers, should not ignore complementary and alternative medicine options. Instead, they should try to determine the rate of complementary and alternative medicine use among their patients and understand their effects and the reasons for use of these agents. Nurses should learn more about these medicines and educate their patients

(Ozlem et al., 2012).

Aims of the study:

This study aims to:

1-Determine the use rate of complementary and alternative medicine among elderly diabetic patients attending Assiut University and Health Insurance Hospitals and identify the sociodemographic features influencing this use.

2-Determine types and reasons for CAM use among the studied patients.

Research question:

What is the rate use of complementary and alternative medicine among elderly diabetic patients?

Subjects and Methods:

Study design:

Descriptive cross-sectional study.

Study Setting:

This study was carried out at diabetes outpatient clinics of Assiut University and Health Insurance Hospitals, which served Assiut Governorate. Assiut district was chosen because it has a greater number of hospitals which offer the health care services for elderly diabetics.

\section{Sample size:}

The sample was calculated by using the following equation:

$$
\mathrm{z}^{2} \mathrm{p} \times \mathrm{q}
$$

$$
\mathrm{d}^{2}
$$

\section{(Lwanga and Lemeshow, 1991)}

Based on the prevalence rate of complementary and alternative medicine use among Type (2) diabetes mellitus patients that estimated in previous study as 41.7\% (Khalil et al., 2013) and a confidence level $95 \%$. Level of significant is less than 0.05 . Accordingly, sample size was estimated to be 374 . The sample was being increased to 400 to avoid non response.

\section{Subjects:}

In the present study 400 randomly selected patients with Type (2) diabetes, 180 males and 220 females, aged 60 years or more were recruited to participate. The sampling population consisted of nearly all people attending diabetes outpatient clinic of Assiut University Hospital in the randomly selected two days of the week during the period of the study their number was 157 patients and the remaining sample was obtained from the out patients diabetes clinic of Health Insurance Hospital; 243 patients who came in the randomly selected four days of the week were invited to participate in the study patients.

\section{Study tools:}

A semi-structured interview questionnaire was designed by the researchers based on relevant literature to assess diabetic patients' uses of complementary and alternative medicine, it included three parts:

Part (1): This part was concerned with sociodemographic characteristics of studied sample such as age, sex, educational status, marital status, religion, occupation and family income.

Part (2): It included medical history of diabetic patients and co-morbidity.

Part (3): It concerned with complementary and alternative medicine use among the studied patients such as use of CAM to regulate blood sugar, types of CAM used in treatment of diabetes, reasons of CAM us etc......

\section{Content Validity:-}

It was established by panel of 5 expertise's who reviewed the instruments for clarity, relevance, comprehensive, understanding, applicability and easiness for administrative minor modification. The content validity of this tool was checked by expert professors in the fields of medicine and nursing and correction was carried out accordingly.

\section{Administrative phase:}

Formal administrative approvals were taken before the start of the study. These included approval by the Ethical Committee of Assiut Faculty of Nursing. An 
official approval letter to the director of outpatient clinics in Assiut University Hospital and director of Health Insurance Hospital.

\section{Data collection:}

Data collection was started from the first of September 2013 to the first week of October 2013. Each patient was interviewed individually to obtain the necessary information after explanation of the study purpose. The average time taken for completing each interview ranged from 20 to 30 minutes depending on the patient's response. Every week about 70-80 questionnaires were completed (two days/ week in Assiut University Hospital and four days/ week in Health Insurance Hospital).

\section{Ethical considerations:}

The researcher explained the purpose and the nature of the study for each patient. The patient had the right to agree or disagree on participation in the study. The patient was informed that the information obtained was confidential and used only for the purpose of the study.

\section{Pilot study:}

Field pre-testing of the questionnaire was carried out before its use to test understanding and wording of the questions. This was done on 20 patients who were not included in the sample. It also helped us to estimate the time needed to administer and fill out the questionnaire and determine the coding system. Minor wording changes were made to clarify the meaning of certain questions.

\section{Statistical analysis:}

The obtained data were reviewed, prepared for computer entry, coded, and analyzed using SPSS statistics software, version 16. Descriptive statistics mean, standard deviation, frequency and percentages were calculated. Chi square test was used to compare qualitative variables between groups. It was considered significant when P-value was less than 0.05 . 


\section{Results:}

Table (1) : Sociodemographic characteristics of elderly diabetic patients attending Assiut University and Health Insurance Hospitals, 2013.

\begin{tabular}{|c|c|c|}
\hline Variable & No. $(n=400)$ & $\%$ \\
\hline \multicolumn{3}{|l|}{ Age (years): } \\
\hline $60-$ & 192 & 48.0 \\
\hline $65-$ & 95 & 23.8 \\
\hline$\geq 70$ & 113 & 28.2 \\
\hline Mean \pm SD (Range) & \multicolumn{2}{|c|}{$65.49 \pm 5.49(60-85)$} \\
\hline \multicolumn{3}{|l|}{ Sex: } \\
\hline Male & 180 & 45.0 \\
\hline Female & 220 & 55.0 \\
\hline \multicolumn{3}{|l|}{ Religion: } \\
\hline Moslem & 343 & 85.8 \\
\hline Christian & 57 & 14.2 \\
\hline \multicolumn{3}{|l|}{ Marital status: } \\
\hline Single & 7 & 1.8 \\
\hline Married & 256 & 64.0 \\
\hline Widowed & 132 & 33.0 \\
\hline Divorced & 5 & 1.2 \\
\hline \multicolumn{3}{|l|}{ Level of education: } \\
\hline Illiterate & 185 & 46.2 \\
\hline Read \& write & 55 & 13.8 \\
\hline Basic education & 31 & 7.7 \\
\hline Secondary & 71 & 17.8 \\
\hline University & 58 & 14.5 \\
\hline \multicolumn{3}{|l|}{ Residence: } \\
\hline Rural & 232 & 58.0 \\
\hline Urban & 168 & 42.0 \\
\hline \multicolumn{3}{|l|}{ Occupation: } \\
\hline Working & 26 & 6.5 \\
\hline Not working & 172 & 43.0 \\
\hline Retired & 202 & 50.5 \\
\hline \multicolumn{3}{|c|}{ Family income per month (LE): } \\
\hline$<500$ & 30 & 7.5 \\
\hline $500-$ & 231 & 57.8 \\
\hline $1000-$ & 86 & 21.5 \\
\hline$\geq 1500$ & 53 & 13.2 \\
\hline
\end{tabular}

Fig. (1) : Co-morbidity among the studied elderly diabetic patients attending Assiut University and Health Insurance Hospitals, 2013.

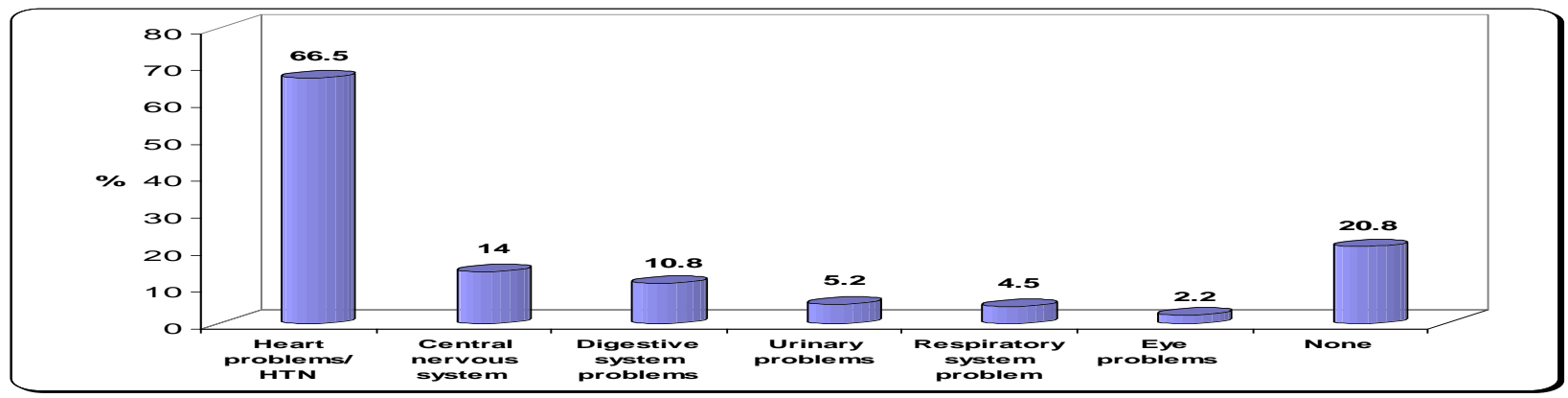


Table (2): Medical history of diabetes mellitus among the studied patients attending Assiut University and Health Insurance Hospitals, 2013.

\begin{tabular}{|c|c|c|}
\hline Variables & No. $(n=400)$ & $\%$ \\
\hline \multicolumn{3}{|l|}{ Duration of diabetes (years): } \\
\hline$<5$ & 122 & 30.5 \\
\hline $5-$ & 101 & 25.2 \\
\hline$\geq 10$ & 177 & 44.2 \\
\hline Mean \pm SD (range) & \multicolumn{2}{|c|}{$8.98 \pm 6.78$ ( 1 month -40 years $)$} \\
\hline \multicolumn{3}{|l|}{ Current treatment: } \\
\hline Diet & 3 & 0.8 \\
\hline Tablets & 298 & 74.5 \\
\hline Insulin & 63 & 15.8 \\
\hline Tablets and insulin & 36 & 9.0 \\
\hline \multicolumn{3}{|l|}{ Pattern of follow-up: } \\
\hline Regular & 362 & 90.5 \\
\hline Irregular & 38 & 9.5 \\
\hline \multicolumn{3}{|l|}{ Place of follow-up: } \\
\hline Assiut University Hospital & 152 & 38.0 \\
\hline Health Insurance (Mabarrah) Hospital & 226 & 56.5 \\
\hline Private clinic & 102 & 25.5 \\
\hline \multicolumn{3}{|c|}{ Number of visits to diabetes clinic per month: } \\
\hline One & 35 & 8.8 \\
\hline Two & 158 & 39.5 \\
\hline Three & 207 & 51.8 \\
\hline \multicolumn{3}{|l|}{ Covered by health insurance: } \\
\hline Covered & 243 & 60.8 \\
\hline Not covered & 157 & 39.2 \\
\hline \multicolumn{3}{|l|}{ Take medication regularity: } \\
\hline Yes & 390 & 97.5 \\
\hline No & 10 & 2.5 \\
\hline \multicolumn{3}{|l|}{ Cause of not taking medication: } \\
\hline Side effects & 1 & 10.0 \\
\hline Forget taking the medications & 9 & 90.0 \\
\hline \multicolumn{3}{|l|}{ Effect of prescribed medication: } \\
\hline Effective & 391 & 97.8 \\
\hline Not effective & 9 & 2.2 \\
\hline
\end{tabular}

Fig. (2): Current use of complementary and alternative medicine among the studied patients attending Assuit University and Health Insurance Hospitals, 2013.

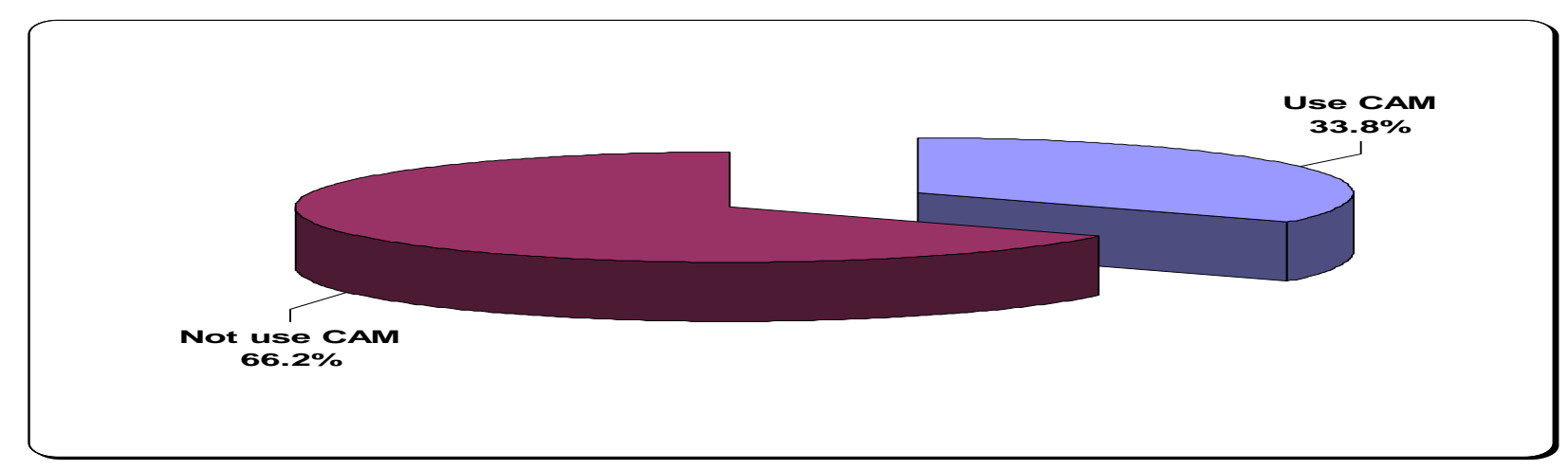


Table (3) : Complementary and alternative medicine use among the studied patients attending Assuit University and Health Insurance Hospitals, 2013.

\begin{tabular}{|c|c|c|}
\hline $\begin{array}{c}\text { Items } \\
\end{array}$ & No. $(n=135)$ & $\%$ \\
\hline $\begin{array}{l}\text { Types of CAM used in treatment of diabetes: } \\
\text { Herbal treatment }\end{array}$ & 134 & 99.3 \\
\hline Herbal and alternative treatment & 1 & 0.7 \\
\hline \multicolumn{3}{|l|}{ Starting CAM use: } \\
\hline Immediately after diagnosis & 71 & 52.6 \\
\hline When sugar level was not controlled & 61 & 45.2 \\
\hline When I had complications of the disease & 3 & 2.2 \\
\hline \multicolumn{3}{|l|}{ Reasons of CAM use ${ }^{\#}$ : } \\
\hline To reduce blood sugar & 129 & 95.6 \\
\hline To feel better & 29 & 21.5 \\
\hline To avoid side effects of pharmaceutical drugs & 34 & 25.2 \\
\hline To overcome dissatisfaction with pharmaceutical drugs & 6 & 4.4 \\
\hline \multicolumn{3}{|l|}{ Expected results from CAM use ${ }^{\#}$ : } \\
\hline Cure of the disease & 34 & 25.2 \\
\hline Improved symptoms/ complications & 84 & 62.2 \\
\hline Complementary to prescribed drugs & 17 & 12.6 \\
\hline Feeling better & 13 & 9.6 \\
\hline \multicolumn{3}{|l|}{ Using CAM alone or with prescribed medication: } \\
\hline Alone & 12 & 8.9 \\
\hline With prescribed medicines & 123 & 91.1 \\
\hline \multicolumn{3}{|l|}{ Effect of CAM use: } \\
\hline Complete cure & 4 & 3.0 \\
\hline Improved symptoms and complications & 93 & 68.9 \\
\hline No improvement & 37 & 27.4 \\
\hline My condition became worse & 1 & 0.7 \\
\hline \multicolumn{3}{|l|}{ Side effects of CAM: } \\
\hline Yes & 1 & 0.7 \\
\hline No & 134 & 99.3 \\
\hline \multicolumn{3}{|l|}{ Costs LE/ month: } \\
\hline$<20$ & 57 & 42.2 \\
\hline $20-<40$ & 63 & 46.7 \\
\hline$>40$ & 15 & 11.1 \\
\hline \multicolumn{3}{|l|}{ Blood sugar checked up frequently during CAM use: } \\
\hline Yes & 134 & 99.3 \\
\hline No & 1 & 0.7 \\
\hline \multicolumn{3}{|l|}{ Health care providers knew that I used CAM: } \\
\hline Yes & 134 & 99.3 \\
\hline No & 1 & 0.7 \\
\hline
\end{tabular}

\# There is more than one answer 
Fig. (3): Satisfaction with complementary and alternative medicine use among the studied patients attending Assuit University and Health Insurance Hospitals, 2013.

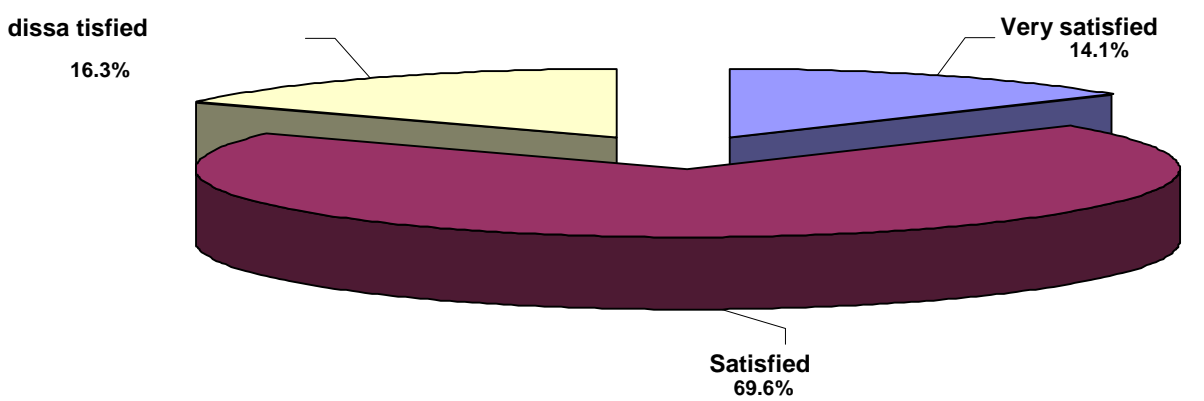

Table (4) : Relationship between sociodemographic characteristics of the studied patients and complementary alternative medicine use, Assiut University and Health Insurance Hospitals, 2013.

\begin{tabular}{|c|c|c|c|c|c|c|}
\hline \multirow{3}{*}{ Variable } & \multicolumn{4}{|c|}{ Use of CAM } & \multirow{3}{*}{$\begin{array}{c}\text { Total } \\
n=400\end{array}$} & \multirow{3}{*}{ P-value } \\
\hline & \multicolumn{2}{|c|}{$\begin{array}{c}\text { Yes } \\
(n=135)\end{array}$} & \multicolumn{2}{|c|}{$\begin{array}{c}\text { No } \\
(n=265)\end{array}$} & & \\
\hline & No. & $\%$ & No. & $\%$ & & \\
\hline \multicolumn{6}{|l|}{ Age (years): } & \multirow{4}{*}{0.345} \\
\hline $60-$ & 58 & 30.2 & 134 & 69.8 & 192 & \\
\hline $65-$ & 36 & 37.9 & 59 & 62.1 & 95 & \\
\hline$\geq 70$ & 41 & 36.3 & 72 & 63.7 & 113 & \\
\hline \multicolumn{6}{|l|}{ Sex: } & \multirow{3}{*}{$0.009 *$} \\
\hline Male & 73 & 40.6 & 107 & 59.4 & 180 & \\
\hline Female & 62 & 28.2 & 158 & 71.8 & 220 & \\
\hline \multicolumn{6}{|l|}{ Level of education: } & \multirow{6}{*}{$0.002 *$} \\
\hline Illiterate & 51 & 27.6 & 134 & 72.8 & 185 & \\
\hline Read and write & 13 & 23.6 & 42 & 76.4 & 55 & \\
\hline Basic education & 10 & 32.3 & 21 & 67.7 & 31 & \\
\hline Secondary & 32 & 45.1 & 39 & 54.9 & 71 & \\
\hline University & 29 & 50.0 & 29 & 50.0 & 58 & \\
\hline \multicolumn{6}{|l|}{ Residence: } & \multirow{3}{*}{0.177} \\
\hline Rural & 72 & 31.0 & 160 & 69.0 & 232 & \\
\hline Urban & 63 & 37.5 & 105 & 62.5 & 168 & \\
\hline
\end{tabular}

* There is statistically significant difference

Table (5) : Relationship between complementary and alternative medicine use and duration of diabetes of the studied patients attending Assiut University and Health Insurance Hospitals, 2013.

\begin{tabular}{|c|c|c|c|c|c|c|}
\hline \multirow{3}{*}{ Duration of diabetes } & \multicolumn{4}{|c|}{ Use of CAM } & \multirow{3}{*}{$\begin{array}{c}\text { Total } \\
(n=400)\end{array}$} & \multirow{3}{*}{ P-value } \\
\hline & \multicolumn{2}{|c|}{$\begin{array}{c}\text { Yes } \\
(\mathbf{n}=\mathbf{1 3 5})\end{array}$} & \multicolumn{2}{|c|}{$\begin{array}{c}\text { No } \\
(n=265)\end{array}$} & & \\
\hline & No. & $\%$ & No. & $\%$ & & \\
\hline$<5$ years & 34 & 27.9 & 88 & 72.1 & 122 & \multirow{3}{*}{0.120} \\
\hline 5 - years & 32 & 31.7 & 69 & 68.3 & 101 & \\
\hline$\geq 10$ years & 69 & 39.0 & 108 & 59.0 & 177 & \\
\hline
\end{tabular}


Table (1) : shows the sociodemographic characteristics of the 400 elderly diabetic patients who included in this study. More than half of the sample $(55.0 \%)$ was females and $45.0 \%$ were males, $48.0 \%$ were in age group $60-<65$ years and $64 \%$ of studied sample were married. $58.0 \%$ resided in rural areas, while $42.0 \%$ were urban residents As regarding the educational level, $46.2 \%$ of studied sample were illiterates, while $14.5 \%$ of them had university education. The income of nearly $58.0 \%$ of the participants was $500-<1000$ LE per month and the half of the studied patients were retirees.

Figure (1) : High percentage of the studied patients $(79.2 \%)$ had heath problems associated with diabetes mellitus. As more than two thirds $(66.5 \%)$ had heart problems and/or hypertension, $14.0 \%$ had neural affection and $10.8 \%$ had troubles in the digestive system.

As shown in Table (2): less than half (44.2\%) of the studied sample had diabetes more than 10 years. Regarding health insurance status about $60.0 \%$ of the studied patients were covered under the umbrella of health insurance. Currently, $74.5 \%$ were on oral hypoglycemic drugs, $15.8 \%$ were on insulin and $9.0 \%$ take both. The vast majority of the patients (97.5\%) take their medication regularly. Only $2.5 \%$ of the respondents did not take the medications on regular bases mainly because they forget taking them on time.

Regarding CAM use, Figure (2) : depicts that $33.8 \%$ of the patients had used some types of CAM therapy to regulate the blood sugar level and the vast majority $(99.3 \%)$ of studied sample was used herbal treatment.

Table (3) : According to reasons of CAM use, $95.6 \%$ of studied sample stated that to reduce blood sugar. More than $90 \%$ of them used CAM with prescribed medications. Regarding the impact of CAM, more than two thirds (68.9\%) stated that they improved the symptoms and complication of diabetes. On the other hand, $27.4 \%$ reported that the herbal treatment had not impact on their condition. $99.3 \%$ of studied sample stated that CAM didn't have any side effect and $97.8 \%$ of them reported that the prescribed medications are more expensive than CAM. Reported costs of medications per month ranged from less than 20 to more than 40 Egyptian pounds

Figure (3) : illustrates patients' satisfaction with CAM use as $14.1 \%$ of CAM users were very satisfied with them and $69.6 \%$ were satisfied. On the other hand, $16.3 \%$ were not satisfied at all.

As shown in Table (4) : the CAM use was more frequent among patients in the age group $65-<70$ years $(37.9 \%)$. More than two thirds $(69.8 \%)$ of the patients who aged $60-<65$ years did not use CAM. Regards to patients' sex, it is observed that the male patients used CAM more than females $(54.1 \%$ versus 45.9, respectively). Also CAM use was more frequently among university educated patients and urban residents (50.0\% and $37.5 \%$, respectively).

Table (5) : shows that there is no statistical significant difference between CAM use and duration of diabetes as $39 \%$ of studied sample who had diabetes more than 10 years used CAM in comparison with $72.1 \%$ who discovered their disease from less than 5 years while they did not use CAM.

\section{Discussion:}

The demographic characteristics of the sample were similar to a study undertaken in the elderly population conducted by Khalil et al. (2013). This finding suggests that the sample was representative of people attending the diabetes clinics in Assiut city and enhances the possibility to transfer the findings beyond our sample. However, the results may not be applicable to other settings.

The percentage of CAM usage among diabetic patients in this study about one third (33.8\%). This is consistent with findings of other studies in the Gulf States such as Saudi Arabia; 30\% (Al-Saeedi et al., 2003), the United Arab Emirates; 38\% (Al-Braik et al., 2008), and in Turkey; $34.6 \%$ (Özlem et al., 2012). The current usage is higher than studies in the United Kingdom; 17\% (Leese et al., 1997), Australia; $23.6 \%$ (Clifford et al., 2003). This is lower compared to studies in Taiwan; $61 \%$ (Chang et al., 2011) and Mexico; 62\% (Argáez-López et al., 2003), and Korea; 65\% (Lee et al., 2004), India; 67.7\% (Kumar et al., 2006), United States of America; 72.8\% (Bell et al., 2006) and in Egypt; 41.7\% (Khalil et al., 2013). The rates of CAM use vary from country to country. This conflicting evidence might be due to differences in beliefs, values, and cultural features of the communities. Lower rates of CAM use in this study can be explained by insufficient trustful source for buying these products or lack of skilled personnel for guiding people for using CAM.

Regarding sociodemographic features that affected use of CAM. In this study, the most frequent users of CAM wereolder than 65 years. This result agrees with other studies conducted in USA by Egede et al. (2002) and in Turkey by Özlem et al. (2012) who reported high rates of CAM use among individuals older than 65 years and those with a high education level. However, Argaez-Lopez et al. (2003) who found that high rates of CAM use among women and individuals with low education levels.

This study showed that more than one third (37.9\%)of the studied patients aged $65-<70$ years are more likely used CAM than other age groups. 
This finding is consistent with study in the USA that identified those aged over 65 years as were three times more likely to use CAM than those aged less than 65 years (Egede et al, 2002). The higher likelihood of CAM use in these groups of patients could be due to the decreasing health status of the patients following an increasing age. They may were anxious about their health condition and therefore have a tendency to seek alternative medication for their diabetes. In the present study, it was found that as the age increased, the use of CAM for diabetes also increased, probably due to fear of side effects due to aging, as well as the disease chronicity. This finding is similar to Egede et al. (2002) and Balamurugan et al. (2013). Contrary to this, younger age diabetics were more likely to visit CAM practitioners, as study conducted by Chi-Wai et al. (2012) and Jeongseon and Mabel (2004). But there is no statistical significant difference between CAM use and age of our patients. These results are consistent with the findings of two studies in the eastern part by Ceylan et al. (2008) and Gözüm et al. (2003) they found that no significant difference in age and CAM usage but contradict those with two studies by Inanç et al. (2007) and Tan et al. (2004) who stated that there is significant difference between age and uses of CAM.

As regard patient sex, in this study two third (40.6\%) of male patients used CAM more than females. This finding is consistence with the finding of Hasan et al. (2011) who conducted study on CAM use among Malaysian patients with diabetes mellitus and reported that male patients $(52.6 \%)$ were the predominant CAM users. This finding contrary with others studies that the elderly female patients were the most frequent users of CAM, which conducted by other researchers (Chi- Wai et al., 2012; Özlem et al., 2012; Balamurugan et al., 2013 Ching et al., 2013). Also Argaez-Lopez et al. (2003) reported high rate of CAM use among women. Bishop and Lewith (2008) conducted a study on a narrative review of demo-graphic characteristics and health factors associated with CAM use, in which reported that female is most frequent users of CAM. And similarly, McMahan and Lutz's (2004) reported greater use of any CAM remedy among women over men age 65-74 years.

In addition, the present study revealed that there is statistical significant relation between CAM usage and sex. This is consistence with studies conducted by Tan et al. (2004) and Inanç et al. (2007) who found that there is a significant difference between sex and CAM usage but contradicts with studies conducted by Gözüm et al. (2003) and Ceylan et al. (2008), Hasan et al. (2011) and Ching et al. (2013) who reported that there is no statistical significant difference between sex and use of CAM.

Concerning patients' education, the CAM use was more frequently among university educated patients $(50 \%)$ with statistical significant difference. This finding is consistence with findings of other studies (Ceylan et al., 2008; Khalaf and Whitford, 2010; Hasan et al., 2011; Chang et al., 2011; Khalil, 2013; Chi- Wai et al. , 2012; Andrews et al., 2012; Ching et al., 2013), where higher educational status were more likely to depend on CAM use with significant difference. And in the same line the study conducted by Leonard et al. (2002) who reported that individuals with high school education and higher were 2.4 times more likely to use CAM than those who had not completed high school. This is contrary to the study of Balamurugan et al. (2013) who reported that illiterate patients were most frequent used CAM and showed that decreasing trend of CAM use among diabetic patient with increase in level of education. Huri et al. (2009) who reported that most of the patients that used CAM had only attained secondary education; this is contrary with the present results. Also Argaez-Lopez et al. (2003) who reported that high rates of CAM use among individuals with low education levels. On other hand, this result disagrees with Özlem et al. (2012) who reported that there was no statistically significant difference between the status of CAM use and respondents' levels of education, and Ching et al. (2013) who found that there is no significant relationship between CAM usage and education level.

According to the percentage of CAM use and residence, more than one third $(37.5 \%)$ of urban patients used CAM compared to $31 \%$ of rural patients with no statistical significance differences between percentage of use and residences. This result agree with Khalil et al. (2013) who reported that $96.1 \%$ of urban patients used CAM more frequently than rural ones $(3.9 \%)$ with no association difference. This finding can be explained by those urban diabetic patients were most likely CAM users because of availability of CAM and easily access. Also, it may be explained by highly socio-economic status, and high educational level. These factors are common in urban areas.

Concerning duration of diabetes, the present study revealed that more than one third $(39 \%)$ of the participants had diabetes for more than 10 years. This is agreed with a study done by Khalil and his colleagues (2013) who reported that higher rate of using CAM is associated with longer duration of diabetes. Also, this result is consistent with the results of the previous studies (Arcury et al., 2006; Ceylan et al., 2008; Chang et al., 2007; Khalaf and 
Whitford, 2010; Özlem et al., 2012), which confirmed an association shown between CAM usage with longer duration of diabetes and the presence of complications. On the other hand, this study disagrees with Balamurugan et al. (2013) who reported that the rate of use of CAM in relation to duration of diabetes was found that majority of the subjects $85.9 \%$ had diabetes of less than 5 yrs duration and it showed a decrease in trend, with increase in duration of diabetes. And contrary with finding of study conducted by Sethi et al. (2011) who found that the maximum of patients with duration of illness less than 5 years have incidence of $90 \%$ use of CAM.

In the present study, there were no statistically significant relationships between CAM usage and duration of diabetes. This similar some studies by Khalil et al. (2013) and Kiran et al. (2012) who reported that there is no statistically significant difference between CAM usage and duration of diabetes. This disagrees with Balamurugan et al. (2013) who reported that there is statistical difference between duration of diabetes and CAM use.

In the current study, the most common types of CAM used among users were herbal remedies (99.3\%). The high consumption is not surprising, since most diabetics presumed that herbs are safer and, additionally, more affordable and easily available (Kaptchuk and Eisenberg, 1998; Dannemann et al., 2008; Hasan et al., 2011). This result is consistent with those of previous studies from other countries (Gözüm and Ünsal, 2004; Algıer et al., 2005; Chang et al., 2007; Inanç et al., 2007; Ceylan et al., 2008; Arıkan et al, 2009; Khalaf and Whitford, 2010; Oreagba et al., 2011; Özlem et al., 2012; Ching et al., 2013) in which the herbal medicine were the most common use among diabetic patients. In a study conducted by Egede et al. (2002) he found that the commonly used CAM in Western countries were nutritional advice and lifestyle diets, spiritual healing, herbal remedies, massage therapy and meditation while MacLennan et al. (2002) described that the most popular forms of CAM among Australians were non-prescribed vitamins, chiropractic, herbal medicines and mineral supplements.

One of the perceived reasons why patients use alternative medicines was because they are effective in lowering their blood sugar while improving their symptoms and complications. The results of this study showed that vast majority of the respondents claim that alternative medicines are effective for reducing blood sugar as the reasons for uses $(95.6 \%)$. As to how effective it was, respondents of this study expected that it improve their symptoms and complications (62.2\%) and the effect after use it $(68.9 \%)$ improve their symptoms and complications.

This result is similar to the results of Mervin (2007) who reported that the alternative medicines were effective $(72 \%)$. As to how effective it was, respondents of this study claimed that it alleviated their symptoms $(68 \%)$ and it decreased their blood sugar level (44\%) and also similar study was conducted by Özlem (2012) and he found that $98 \%$ of diabetic patients used CAM for reducing blood sugar and $84 \%$ of patients reported decreased of blood sugar after used it.

However, the efficacy could not be totally attributed to the use of alternative medicines as the vast majority of the patients used alternative medicines together with the prescribed medicines. Perhaps it just had a complementary effect with the prescribed medicine in lowering their blood sugar but nonetheless the respondents believed that the alternative medicine was giving the effect. This finding is consistence with other studies (Egede et al., 2002; Huri et al. 2009; Ching et al. 2013; AlKindi et al., 2011) which found that diabetic patient used CAM in addition to prescribed medication. Also, Mervin (2007) reported that about 57\% of the patients use alternative medicines together with the prescribed medicines.

In contrast, these results disagreed with studies conducted by Dunning (2003), Miller et al. (2008) and Chang et al. (2011) who reported that the majority of participants primarily used CAM for other health-related conditions; to relieve symptoms related to conditions other than Type (2) diabetes, to maintain body health, and to improve energy.

In the present study, the vast majority of the patients who used CAM reported that CAM had not side effects. They also did not stop using conventional medicine, but used it simultaneously with CAM. On the other hand, this result disagrees with several cases reported unwanted effects due to CAM combined with conventional medicine (Dunning, 2003; Wood et al., 2004). In addition, Clifford et al. (2003) reported that $43 \%$ of the individuals with diabetes using CAM were likely to experience adverse drug interactions and that stricter supervision of CAM use was needed for protection against these negative effects.

In the current study nearly all of the studied patients $(99.3 \%)$ their care providers knew that they used CAM with the pharmaceutical medications. This percentage is higher than that reported in other studies. For example, Özlem et al. (2012) reported that $73 \%$ of their patients didn't informed health care providers with used CAM. However; these findings are contradicted with findings of Huri et al. (2009) who reported that less than a quarter of the CAM 
users informed their physicians about their CAM use and study by Chang et al. (2011) who reported that only $24.6 \%$ had disclosed their CAM use to a healthcare professional. A study in Singapore Lim et al. (2005) also found similar condition where only a small percentage of patients discussed their CAM use with their physician. Egede and his colleagues (2002) found that fewer than $40 \%$ of Americans with diabetes who used CAM disclosed this information to their physicians. Lack of communication between the physicians and the patients and lack of time for counseling may be the reasons for this finding. Also, this result may be explained by that patients may be worried regarding the negative attitude of doctors toward the use of CAM so they do not inform their doctors about it.

In this study, the CAM use was more frequent among patients in the age group $65-<70$ years $(37.9 \%)$. Male patients used CAM more than females $(54.1 \%$ versus 45.9, respectively). Also CAM use was more frequently among university educated patients and urban residents $(50.0 \%$ and $37.5 \%$, respectively). Also, Kumar and other researchers (2006) found that higher level of education was significant positive correlates of CAM use among diabetic patients attending Nehru Hospital, Allahabad, India.

This study presents the findings of a survey and is subject to the limitations of self-reported data. Most of the present study items were neutral. However, undoubtedly the respondents would want to appear to be knowledgeable and may have misstated their actual herb use. In addition, because this survey was administered in health care clinics, the responses to items relating to physicians may have recall bias. In addition, this study did not investigate the effectiveness of CAM on diabetes, such as showing that patients' blood glucose was controlled on CAM or not.

\section{Conclusions:}

Based on the results and research question of the present study, it can be concluded that:

The majority of the studied patients had heath problems associated with diabetes mellitus. Less than half of the studied sample had diabetes more than 10 years. More than one third of the patients had used some type of CAM therapy to regulate the blood sugar level and the vast majority of them used herbal treatment. The CAM use was more frequent among patients in the age group $65-<70$ years and male patients. Also CAM use was more frequently among university educated patients and urban residents. There is statistical significant difference between CAM use and sex and level of education of our Recommendahns:

\section{The study recommended that:}

- Diabetic patients need a regular, systematic education throughout their lives. This is to be informed about the new principles and procedures in the treatment of diabetes.

- Up-to-date scientific CAM information should be provided to patients and their social networks such as family.

- Further research will be required involving many regions and to obtain data on any health benefits achieved through CAM usage.

\section{Acknowledgements}

We express great thanks to all patients who kindly participated in this study for their cooperation. Also, we would like to extend our deepest gratitude to $\mathbf{M r}$. Saad Eldeen Mohamed for his great help.

\section{References:}

1. Abd El- Maksoud H A, Afaf DA and Sahar A M (2009): Biochemical studies on the influence of certain herbs in streptozotocin induced diabetic rats. Third Interventional Scientific Conference, Banha and Ras Suder Egypt; 294230.

2. Al-Braik FA, Rutter PM and Brown DA (2008): cross-sectional survey of herbal remedy taking by United Arab Emirate (UAE) citizens in Abu Dhabi. Pharmacoepidemiol Drug Saf.; 17:725-732.

3. Algıer L, Hanoğlu Z, Özden G, and Kara F (2005): The use of complementary and alternative (non-conventional) medicine in cancer patients in Turkey. European Journal of Oncology Nursing; 9: 138-146.

4. Al-Kindi MR, Al-Rabaani AM, Al-Mushrafi M, and Ibrahim A. (2011): Complementary and Alternative Medicine Use among Adults with Diabetes in Muscat Region, Oman. Sultan Qaboos Univ Med J.; 11 (1): 62-68.

5. Al-Saeedi M, Elzubier AG, Bahnassi AA and Al-Dawood KM (2003): Pattern of belief and use of traditional remedies by diabetic patients in Mecca, Saudi Arabia. East Mediterr Health J.; 9:99-107.

6. Andrews G, Adams J and Segrott J (2012): The prevalence and profile of CAM users and reasons for use, in Tradition, Complementary and Integrative Medicine: An International Reader, J. Adams, G. Andrews, J. Barnes et al., Eds., Palgrave- Macmillan, London, UK

7. Arcury T, Bell R, Snively B, Smith S, Skelly A, Wetmore $L$ and Quandt $S$ (2006): Complementary and alternative medicine use as health self- management: rural older adults with 
diabetes. J Geront B Psychol Sci Soc Sci.; 61(2): S62-S70.

8. Argaez L'opez N, Wacher NH and KumateRodr' iguez J (2003): The use of complementary and alternative medicine therapies in type 2 diabetic patients in Mexico. Diabetes Care; 26(8): 2470-2471.

9. Arıkan D, Sivrikaya S and Olgun N (2009): Complementary alternative medicine uses in children with type 1 diabetes mellitus in Erzurum, Turkey. Journal of Clinical Nursing; 18: 2136-2144.

10. Balamurugan S, Swathi $S$ and Kannan $C$ (2013): Prevalence and pattern of use of complementary and alternative medicines by the patients with diabetes attending a tertiary care centre in Salem, Tamil Nadu. Nat.J.Res.Com.Med .; 2(1): 1 - 78

11. Bell RA, Suerken CK, Grzywacz JG, Lang W, Quandt SA, and Arcury TA (2006): Complementary and alternative medicine use among adults with diabetes in the United States. Alternat Ther Health Med.; 12:16-22.

12. Bishop FL and Lewith GT (2008): Who uses CAM? A narrative review of demo-graphic characteristics and health factors associated with CAM use. Evid Based Complement Alternat Med.

13. CDC (2011): Center of disease control and prevention Located on http://www.cdc.gov/ diabetes.

14. Ceylan S, Azal O, Taşlipinar A, Türker T, Açikel CH and Gulec $M$ (2008): Complementary and alternative medicine use among Turkish diabetes patients. Complement Ther Med.; 17:78-83.

15. Chang $\mathbf{H} \mathbf{Y A}$, Wallis $M$, and Tiralongo $\mathbf{E}$ (2011): Use of complementary and alternative medicine among people with type 2 diabetes in Taiwan: a cross-sectional survey. EvidenceBased Complementary and Alternative Medicine; Article ID 983792, 8.

16. Chang $H$, Wallis $M$, and Tiralongo $E$ (2007): Use of complementary and alternative medicine among people living with diabetes: Literature review. Journal of Advanced Nursing; 58: $307-$ 319.

17. Ching SM, Zakaria ZA, Fuziah $P$ and Mehrdad J (2013): Complementary alternative medicine uses among patients with type 2 diabetes mellitus in the primary care setting: a cross-sectional study in Malaysia. BMC Complementary and Alternative Medicine; 13:148.

18. Chi-Wai Lui, Jo dowee, Maria Donald and Joseph R. Coll (2012): Patterns \& determinants of CAM practitioner use among adults with diabetes in Queensland, Austialia. EvidenceBased CAM

19. Clifford RM, Batty KT, Davis W, and Davis TM (2003): Prevalence and predictors of complementary medicine usage in diabetes: Fremantle Diabetes Study. Journal of Pharmacy Practice and Research; 33: 260-264

20. Dannemann $K$, Hecker W, Haberland $H$, Herbst A, Galler A, Schäfer T, Brähler E, Kiess W and Kapellen TM (2008): Use of complementary and alternative medicine in children with type 1 diabetes mellitus prevalence, patterns of use, and costs. Pediatr Diabetes; 9:228-235.

21. Dunning T (2003): Complementary therapies and diabetes. Complementary Therapies in Nursing and Midwifery; 9 (2): 74-80.

22. Egede LE (2004): Complementary and alternative medicine use with diabetes. Geriatric Times; 5(3): 8-11.

23. Egede LE, Ye X, Zheng $D$ and Silverstein MD (2002): The prevalence and pattern of complementary and alternative medicine use in individuals with diabetes. Diabetes Care, 25:324329.

24. Forouhar E and Paul S (2012): Non-traditional therapies for diabetes: fact or fiction. Journal of Community Hospital Internal Medicine; 2:1-5.

25. Franklin J, Thana VJ and Ellis P (2011): Body mass index as a guide for diagnosing prediabetes and diabetes. J Nurse Pract.; 7:634-640.

26. Garrow D and Egedel L (2006): Association between complementary and alternative medicine use, preventive care practices, and use of conventional medical services among adults with diabetes. Diabetes Care; 29: 15- 19.

27. Gözüm S and Ünsal A (2004): Use of herbal therapies by older, community-dwelling women. Journal of Advanced Nursing; 46: 171-178.

28. Gözüm S, Tezel $A$ and Koç $M$ (2003): Complementary alternative treatments used by patients with cancer in Eastern Turkey. Cancer Nursing; 26: 230-236.

29. Hasan SS, Loon WC, Ahmadi K, Ahmed SI and Bukhari NI (2011): Reasons, perceived efficacy and factors associated with complementary and alternative medicine use among Malaysian patients with diabetes mellitus. British Journal of Diabetes and Vascular Disease; 11 (2): 92-98.

30. Huri H Z, Lian GTP, Samsinah H, Rokiah P and Riyanto TW (2009): A survey amongst Complementary Alternative Medicine (CAM) users with type 2 diabetes. Int $\mathrm{J}$ Diabetes and Metabolism; 17:9-15. 
31. Inanç $\mathbf{N}$, Çiçek $B$ and Şahin $H$ (2007): Use of herbs by the patients with diabetes in Kayseri, Turkey. Pakistan Journal of Nutrition, 6: 310312.

32. Jeongseon $K$ and Mabel $M$ (2004): Factors influencing preferences for Alternative medicine by Korean Americans. AM.J.Chin.Med ; 32:321.

33. Kaptchuk TJ and Eisenberg DM (1998): The persuasive appeal of alternative medicine. Ann Intern Med.; 129:1061-1065.

34. Khalaf AJ and Whitford DL (2010): The use of complementary and alternative medicine by patients with diabetes mellitus in Bahrain: a cross-sectional study. BMC Complement Alternat Med.; 10:35.

35. Khalil SH, Zaki A, Ibrahim AM, El-Moughazi AM, Khater AM, Youssef AM, El-Sa'ed AT and Rashed EM (2013): Pattern of use of complementary and alternative medicine among Type (2) diabetes mellitus patients in Alexandria, Egypt. J Egypt Public Health Assoc.; 88(3):137142.

36. Kiran M, Bernad C and Trisha D (2012): The use of complementary and alternative medicine among people living with diabetes in Sydney. BMC Complement Altern Med.; 12: 2-6.

37. Kumar D, Bajij S and Mehrotra R (2006): Knowledge, attitude and practice of complementary and alternative medicines for diabetes. Public Health;120:705-711.

38. Lee MS, Lim HJ and Moon SR (2004): Survey of the use of complementary and alternative medicine among Korean diabetes mellitus patients. Pharmacoepidemiol Drug Saf. ;13:167171.

39. Leese GP, Gill GV and Houghton GM (1997): Prevalence of complementary medicine usage within a diabetes clinic. Practical Diabetes; 14:207-208

40. Leonard E, Xiaobou Ye, Deyi Zheng and Marc D. Silverstein (2002): The prevalence and pattern of complementary and alternative Medicine use in individuals with diabetes. Diabetes Care; 25(2): 324-329.

41. Lim MK, Sadarangani $P$, Chan HL and Heng JY (2005): Complementary and alter-native medicine use in multiracial Singapore. Complement Ther Med.; 16:13-24.

42. Lwanga $S$ and Lemeshow $S$ (1991): Sample size determination in health studies. A practical manual, WHO, Geneva, 80.

43. MacLennan AH, Wilson DH and Taylor AW (2002): The escalating cost and prevalence of alternative medicine. Prev Med; 35:166-173.

44. McMahan $S$ and Lutz $R$ (2004): Alternative therapy use among the young-old (ages 65 to
74): an evaluation of the MIDUS database. J Appl Gerontol.; 23:91-103.

45. McWhorter LS (2009): Dietary supplements for diabetes: an evaluation of commonly used products. Diabetes Spectrum; 22: 206-213.

46. Mervin B (2007): The use of alternative medicine among diabetic patients at the diabetic clinic of the Zamboanga City Medical Center; 31-41.

47. Miller JL, Binns HJ and Brickman WJ (2008): Complementary and alternative medicine use in children with type 1 diabetes: a pilot survey of parents. Explore; 4(5):311-314.

48. NCCAM (2010a): What is CAM? National Center for Complementary and Alternative Medicine and Available from http://nccam.nih.gov/health/ whatiscam/overview.htm.

49. Özlem K, Sevgi K, Hatice M, Ozlem U, Dilek BB and Elif U (2012): Complementary and Alternative Medicine Use Among People with Diabetes in Turkey. Western Journal of Nursing Research; 34 (7) 902-916.

50. Saad B, Cooper E and Said O (2008): Traditional Arabic and Islamic Medicine (TAIM) now join TCM, CAM, Kampo and Ayurveda. Evid based Complement Altern Med.

51. Sethi A, Saurabh $S$ and Madhu S V (2011): Prevalence and pattern of use of indigenous medicine in diabetic patients attending tertiary care centre. J Indian Med Assoc; 109:469-471.

52. WHO (2011): Diabetes: Key Facts, World Health Organization, Geneva, Switzerland.

53. Wood DM, Athwal $S$ and Panahloo A (2004): The advantages and disadvantages of a herbal medicine in a patient with diabetes mellitus: A case report. Diabetes Medicine; 21: 625-627. 